\title{
Healthcare Professionals' Perceptions of Support for Family Members in Specialist Palliative Care Inpatient Units - a Qualitative Descriptive Study
}

\author{
Anu Soikkeli-Jalonen ( $\sim$ apsoik@utu.fi ) \\ Turun Yliopisto https://orcid.org/0000-0002-6223-9880 \\ Kaisa Mishina \\ University of Turku: Turun Yliopisto \\ Heli Virtanen \\ University of Turku: Turun Yliopisto \\ Andreas Charalambous \\ Cyprus University of Technology: Technologiko Panepistemio Kyprou

\section{Elina Haavisto} \\ University of Tampere: Tampereen Yliopisto
}

\section{Research Article}

Keywords: Palliative care, Families, Hospital, Interprofessional health care, Qualitative

Posted Date: November 9th, 2021

DOl: https://doi.org/10.21203/rs.3.rs-926664/v1

License: (9) This work is licensed under a Creative Commons Attribution 4.0 International License. Read Full License 


\section{Abstract}

Purpose: The aim of this study was to describe healthcare professionals' (HCPs) perceptions of the support for family members (FMs) of palliative care cancer patients in specialist palliative inpatient units.

Methods: A qualitative descriptive design was applied. The data were collected with focus group interviews and analysed with inductive content analysis.

Results: Information sharing was recognised as an essential element of support. Also, emotional support, discussions and additional support were offered. Practices to improve support of FMs included a possibility to allocate recourses to the families, systematic support and strengthening HCPs' competence in family care.

Conclusions: The opportunities to implement support focusing directly on FMs were described as restricted. Organisational resources were limited in inpatient units. HCPs felt that they did not have enough time to spend with FMs, and the facilities were also not always suitable to support FMs' presence and participation. Therefore, there is a need for systematic support and interventions for FMs that could be implemented in inpatient units by the HCPs as a part of the daily care. Furthermore, additional training for the HCPs in palliative family care is needed.

\section{Background}

Health care professionals (HCPs) play an essential role in supporting family members (FMs) of palliative care patients [1]. Particularly in inpatient care, where FMs value the professional and safe care of the patient, they expect support from the HCPs, including empathy, compassion, involvement in the care and privacy regarding their personal space [2]. Furthermore, bereavement support is beneficial to help with grief management and for FMs to cope psychologically [3]. However, even though FMs experience better support in palliative care units than in other care settings, they still report inadequate support and information sharing [4].

Supporting FMs living in a distressing situation is complex, and improving FMs' well-being can be challenging [5]. It has also been stated that the health care system is designed mainly for the patients, with the FMs' needs coming second, and there is a lack of support aimed at families [6]. In addition, the physical care environment, culture, and attitudes towards the FMs in the care unit enable or hinder the realisation of support [7].

Moreover, FMs have an essential role in offering emotional support to the patient and their willingness to be close to the patient's life and care should be supported [7]. The chance to participate in the care activities and be seen and noticed by the HCPs is significant to FMs [2]. Appropriate information sharing about a patient's diagnosis and dying benefits the FMs [6]. By sharing information, HCPs will explain the patient's deteriorating condition and tailor the information to the individual's ability to accept it [8]. 
However, a patient's right to refuse information sharing also needs to be considered, and HCPs cannot always involve FMs due to confidentiality issues [6].

HCPs do not necessarily have sufficient competence to support FMs in a palliative care context, and they generally have more knowledge about the physical aspects of the care process [6]. Supporting FMs has not been the main focus in palliative care training [9] despite the reports of the lack of education in carer support and the need for training in communication with families [6]. That can lead to problems in recognising FMs' needs and implementing support [9].

The importance of supporting FMs has been acknowledged [1, 3, 6, 7], and it is known that the support is not always optimal [4, 9]. In addition, HCPs face challenges looking after the families $[6,8]$. Some studies concerning support for FMs in an oncology setting in general [10], but the number of studies about supporting FMs in inpatient palliative care is rare [5]. Not many studies disclose how support is provided in a palliative care setting from the viewpoint of HCPs and their opportunities for implementing support in daily care [6]. The role of families in inpatient care needs further study, as families can easily feel like outsiders in a foreign hospital environment and need support to find their own space and position there [7]. Knowledge about HCPs' training needs in palliative family care in the different occupational groups is also needed [9].

\section{AIM}

The aim of this study was to describe HCPs' perceptions of the support for FMs of palliative care cancer patients in specialist palliative inpatient units. The research questions were: 1) what support HCPs provide FMs, and 2) how support for FMs could be improved?

\section{Method}

\section{Study design and setting}

A qualitative descriptive design was applied. The study was conducted in four units, representing typical specialist palliative care units in two large hospital districts in southern (COUNTRY blinded for review), with a total population over 2.1 million, covering approximately $40 \%$ of the (COUNTRY blinded for review) population. Specialist palliative care can be described as holistic care for patients and families, and the HCPs working in specialist units are expected to have specialist expertise [11]. In (COUNTRY blinded for review), specialist palliative care is centralised in units whose primary task is arranging palliative care, including end-of-life care. According to official guidelines, the care personnel is recommended to have special palliative care training [12].

\section{Participants}

The purposive sampling method was used to find informants who had the most appropriate views and understanding of the research subject [13]. HCPs responsible for planning and performing the actual daily care of palliative care patients and their families were all invited. The inclusion criteria for HCPs 
were either doctors, registered nurses or practical nurses who were permanently employed in a specialist palliative care inpatient unit. All those willing to participate were included.

\section{Data collection}

Data were collected from May to September 2019 by three female interviewers (a Bachelor in Nursing Science, PhD-student and PhD), all registered nurses, but with no professional relationship to the participants. Before the interviews, the participants were informed about the interviewers' role and position in the research project. The recruitment was based on voluntary participation, and information about the study was revealed to the participating organisations before the recruitment. The number of participants in the different occupational groups was proportional to the number of professionals working there. The interviewer conducted the interviews in a quiet room in a hospital environment, where participation was easy to implement concerning the work requirements of the participants. The interview questions were based on the study questions but open and broad to enable HCPs to express their perceptions widely. Data collection was carefully planned to ensure the consistency of the interviews.

The data were collected either through focus group interviews to provoke a lively debate with different views on the subject [13], with interviews with two persons, or as individual interviews, if participation in the group interview could not be arranged. The interviews with pairs or individuals were mainly done with doctors, as not many of them work in the same unit, and their participation in the focus groups was not possible. Demographic information about participants was collected, and it is presented in Table 1. Data collection continued until saturation was reached. All interviews were recorded via audio. 
Table 1

Health care professionals' perspectives of support for family members

\section{Sub-category}

Care meetings

General information sharing

Getting a family member to understand a patient's situation

Providing direct information

Respecting a patient's will to deny information sharing with family

Taking care of family members' well-being

Organising additional support for

a family member

Creating confidence that a patient receives good care

Enabling the presence of family members

Encouraging family members' participation

HCP's compassionate presence with the family members

Discussing with the family members

A better physical environment for families

More time for encounters with the families

Better consideration of family support

Development of bereavement

support

Informal events for families

Better communication skills

Education about family care
Category

Keeping the family member informed of the care

Requirements for information sharing

\section{Main category}

Support by providing information to family members
Support concentrating on family members' needs
Emotional support for family members
Supporting family members' and patients' togetherness

Supportive encounters

Allocating resources to the family members support
Practices to improve support for family members 


\section{Data analysis}

Inductive content analysis was used [14]. At the first stage, recorded interviews were transcribed verbatim. The duration of the interviews ranged between 36 minutes to 2 hours and 50 minutes (Table 1), and the transcribed material contained 248 A4 pages with single line spacing. Second, the entire document was read through multiple times to form a general understanding of the data. When familiarisation with the data was completed, the unit of analysis was selected. In this study, that was a sentence or expression longer than one word that described an HCP's perception. During the analysis process, the units of analysis were tabulated, simplified expressions for them were constituted and then coded by one researcher. After tabulating and coding the data, the inductive content analysis was performed by four researchers. Sub-categories were formed by combining related codes of the expressions. The analysis generated categories and united similar sub-categories, finally combining categories into main categories (Table 2). The consolidated criteria for reporting qualitative studies (COREQ): 32-item checklist was used during the analysis and reporting process [15]. 
Table 2

Health care professionals' perspectives of support for family members

Quotes

FGN3: "We arrange care meetings with family members or together with family members, and a doctor, a nurse, relatives and the patient are present".

FGPN1: "If there are any questions regarding the disease or prognosis... then yes, it is a doctor (who shares the information)".

FGP2: "The best way (to share information with a family member) is to have the patient's family members involved during the appointment".

FGP2: "We tell them about the disease and possible future symptoms and what to do and whom to contact (how to support)".

General

information

sharing

FGN4: "We always meet (the family members), or if they don't come to the ward, then we call, we get in touch anyway".

FGPN1: "Some family members want to know how the patient has been, if there have been any symptoms and then, whether they have slept and eaten, if they have been awake and if they have been well".

FGPN2: "We call very quickly if there are any changes in a condition, in one way or another".

FGN1: "You can then touch the patient gently. Here, they are sleeping, they look calm, our medication is working, they don't need to suffer anymore".

FGN3: "We repeat the fact that the situation seems bad, that it is not known if the patient will see the next morning".

FGN6: "Family members want to know more about everything now. You have to know how to explain everything and go through those things a lot more than before".

FGN3: "Or to justify why an unconscious patient is not given a nasogastric tube and nutrition through that".

\section{Sub-category Category}

Care meetings

Keeping the family member informed of the care
Main category

Support by providing information to family members
Getting a

family member to understand a patient's situation
Requirements

for information sharing 


\section{Quotes}

Sub-category

Category

Main

category

FGP2: "To be honest with patients and family members and use the word death as well, to use the right terms. To not use a figure of speech or metaphor that someone does not understand".

FGP1: "Sometimes, you are forced to say things very directly to family members, even though they may not want to hear it".

FGN3: "We must then respect the fact that the patient does not want information shared with family members".

FGPN3: "If the patient says that they do not want anyone to be given information, then I have to agree. No matter how angry that family member is, I must respect that patient's right to selfdetermination".

FGN8: "I often say, 'try to take care of yourself, get some rest, go outside for a while, or sometimes just "have you remembered to take your own medicine?"

FGP1: "We also need to evaluate how the family member is doing".

FGP1: "The wishes have been recorded by the palliative care coordinator, and the wishes of the family members have been taken into account".

FGN2: "If there is an acute case where the patient has just died, then we will contact the crisis services".

FGP2: "You can also ask if the family member wants a conversation with the hospital pastor".

FGPN3: "And creating a safe, confident feeling for family members so that they were able to leave here and have trust".

FGP1: "The feeling of security that conveys a sense that the patient is well cared for".

FGN7: "They can always come here, they can always be here and are always welcome".

FGP1: "Whenever there is a single room... and of course, the aim is to have a single room if a family member wants to stay".
Providing direct information
Respecting a patient's will to deny information sharing with family
Taking care of family members' wellbeing
Support concentrating on family members' needs
Emotional support for family members
Organising additional support for a family member
Creating confidence that a patient receives good care

Enabling the
presence of
family
members

Enabling the presence of members
Supporting

family members' and patients' togetherness 


\section{Quotes}

Sub-category

Category

Main

category

FGN1: "That's how we make the family members feel useful because basic care is what they can participate in. They can help with the feeding and bathing and take care of those things".

FGP1: "I usually encourage family members to come to the care unit; if they hesitate at all, their presence cannot be replaced later".

FGN3: "In that way, they should be treated more gently, however, because the situation is always unique... so remember that it is a truly unique situation for that family".

FGPN1: "And you can say: 'I can stay here with you for a little while. There's nothing to fear".

FGP2: "We aim to talk to family members, sometimes even more often than with the patient".

FGN4: "Some families are very open; they want to discuss everything... Some withdraw, they don't want to talk... and you should be able to respond to it".

FGN5: "So also listen to family members; they often want to tell stories about the patient or this situation and go through the illness".

FGPN3: "So that (a family member) can say goodbye, and then we support them by listening to those stories and are guided in these matters".

FGN6: "There could be a space, a room for the families, and they could even make coffee whenever they wanted to".

FGPN3: "Well, that we could have a space where you could discuss with a family member because we are not allowed to have conversations at the doors of the rooms".

FGN7: "Here, they just look at the number of patients and not at all at how much time we spend on the phone talking to family members. It is not a concrete task and cannot be scheduled, and there should be more time for it".

FGP2: "If Thursday's schedule has three family meetings and ten new patients, then there is not enough time (to take the family members into account).
Encouraging

family

members'

participation
HCP's

compassionate

presence with

the family

members
Supportive

encounters
Discussing with the family members
A better

physical

environment

for families
More time for encounters with the families
Allocating resources to the family members support
Practices to improve support for family members 


\begin{tabular}{|c|c|c|c|}
\hline Quotes & Sub-category & Category & $\begin{array}{l}\text { Main } \\
\text { category }\end{array}$ \\
\hline $\begin{array}{l}\text { FGP2: "Perhaps a certain systematicity in that } \\
\text { support would make it available to everyone } \\
\text { according to some structure". } \\
\text { FGN3: "That family members could be involved at } \\
\text { an earlier stage... that they too could hear those } \\
\text { things in advance". }\end{array}$ & $\begin{array}{l}\text { Better } \\
\text { consideration } \\
\text { of family } \\
\text { support }\end{array}$ & \multirow[t]{5}{*}{$\begin{array}{l}\text { Coordinated } \\
\text { formal and } \\
\text { informal } \\
\text { support for } \\
\text { family } \\
\text { members }\end{array}$} & \\
\hline $\begin{array}{l}\text { FGN2: "What I would like to see developed would } \\
\text { be such bereavement support for family } \\
\text { members". }\end{array}$ & \multirow[t]{2}{*}{$\begin{array}{l}\text { Development } \\
\text { of bereavement } \\
\text { support }\end{array}$} & & \\
\hline $\begin{array}{l}\text { FGP2: "Bereavement support, taking care of } \\
\text { family members after a patient's death, a } \\
\text { monitoring system, should be developed". }\end{array}$ & & & \\
\hline $\begin{array}{l}\text { FGPN2: "Cooperation with family members } \\
\text { should start to be mapped out, or if they want to } \\
\text { network and talk to each other, such an event } \\
\text { should be organised for them". }\end{array}$ & \multirow[t]{2}{*}{$\begin{array}{l}\text { Informal events } \\
\text { for families }\end{array}$} & & \\
\hline $\begin{array}{l}\text { FGP2: "Family members' evenings or something } \\
\text { like that could be to meet the health care staff too, } \\
\text { and maybe family members could find support } \\
\text { from each other". }\end{array}$ & & & \\
\hline $\begin{array}{l}\text { FGPN2: "There should be someone who would } \\
\text { come here to train us (about dealing with family } \\
\text { members); interacting here is so important, and } \\
\text { meeting with family members is highlighted". }\end{array}$ & \multirow[t]{2}{*}{$\begin{array}{l}\text { Better } \\
\text { communication } \\
\text { skills }\end{array}$} & \multirow[t]{4}{*}{$\begin{array}{l}\text { Developing } \\
\text { personnel's } \\
\text { competence }\end{array}$} & \\
\hline $\begin{array}{l}\text { FGP2: "So we could develop our own } \\
\text { communication". }\end{array}$ & & & \\
\hline FGPN1: "It would be nice to have some training". & \multirow{2}{*}{$\begin{array}{l}\text { Education } \\
\text { about family } \\
\text { care }\end{array}$} & & \\
\hline $\begin{array}{l}\text { FGP1: "Education and experience are probably the } \\
\text { best teachers (how to improve support)". }\end{array}$ & & & \\
\hline
\end{tabular}

\section{Results}

The age of the participants ranged from 19-62 years (mean: 43 years). Other demographic information is presented in Table 1.

\section{Health care professionals' perspectives of support}

The HCPs' perspectives of support for FMs produced three main categories: support by providing information to family members, emotional support for family members and practices to improve support for family members. The categorisation and quotes are shown in Table 2. 


\section{Support by providing information to family members}

The first main category contained two categories: keeping the family member informed of the care and requirements for information sharing.

Keeping the family member informed of the care was implemented by FMs presence at the care meetings, where a patient's situation was discussed and planned. During the care meetings, the physician's role was emphasised, and new information about a patient's condition or prognosis was seen as the physician's responsibility to share. It was also mentioned that physicians spent a lot of time meeting and talking with FMs. General information sharing verbally, or by giving information leaflets, calling or being in touch and keeping the FMs up to date in any way was described as a standard supportive procedure. In addition, the HCPs shared information about care, symptoms and the overall disease with FMs. The shared information was strongly related to a patient's daily condition, symptoms, changes in medication, deterioration, or even death.

The category requirements for information sharing concerned the objectives and conditions to be considered when information was shared. The HCPs, particularly nurses and practical nurses, perceived that getting a family member to understand a patient's situation was important when sharing the information. The HCPs supported FMs to understand that the situation was permanent, that the patient's condition was not getting better, and that death was approaching in some cases. The HCPs also needed to justify treatments that were carried out with the patient care by sharing the details about different care procedures, for example, explaining the decisions made regarding nutrition and medication. All the information sharing in the palliative care situation required providing direct information to the FMs, which was highlighted especially by physicians. They needed to be straightforward and express themselves with concise language, honestly, even if the FM did not want to know all of the information. The HCPs also faced situations when they had to respect a patient's will to deny information sharing with family. If the patient did not want the information regarding their condition and care to be shared, the HCPs did not have any other option than to protect their rights, even if a FM insisted on being informed.

\section{Emotional support for family members}

The second main category consisted of three categories: support concentrating on family members' needs, supporting family members' and patients' togetherness, and supportive encounters.

Support concentrating on family members' needs described the support targeted to enhance the FMs' coping. Taking care of family members' well-being assisted FMs coping. For example, the HCPs asked the FMs if they were taking care of their physical health, eating, sleeping and taking their medication. In addition, they made sure that FMs had enough rest and sometimes encouraged them to go home for a while to take a break. Besides, the HCPs took FMs' wishes into account, and they were asked what they were hoping. For example, perhaps they wanted to bring a favourite dish or even pets to the care unit, and their specific religious and cultural needs were respected. The HCPs supported FMs by organising additional support and making appointments with other professionals who could help them in a crisis 
and challenging situations, like a psychologist, hospital pastor, or crisis centre. Creating confidence that the patient receives good care was a supportive element that the HCPs described as meaningful to FMs. Creating an atmosphere and feeling of safety around the patient created trust and confidence in the care. The HCPs perceived that this confidence in the care helped FMs release their responsibilities and relax.

The category supporting family members' and patients' togetherness included matters that made FMs' involvement in the patient's life easier in the hospital environment. The HCPs were enabling the presence of family members so that FMs could be in the care unit outside of visiting hours; they could stay overnight and be free to come and go as they wanted. The HCPs also tried to arrange a dedicated space for the FMs and private rooms for the patients. Encouraging family members' participation meant they were encouraged to come to the care unit, spend time with the patient, and participate in the care procedures despite the patient's condition.

Supportive encounters were implemented by being present, discussing and listening to the FMs. HCP's compassionate presence with the family members was described as warm, understanding encounters with the FMs, gently taking into account the uniqueness of the situation, hugging and talking with a soothing tone to create a calm atmosphere. Discussing with the family members was experienced as a vital element of support, and the HCPs talked with FMs according to their needs and wishes. Therefore, discussions with FMs were perceived to take place even more frequently than discussions with patients. During the discussions, the HCPs listened to FMs' stories about the patient, the FMs' situation, and they asked questions to help them express themselves.

\section{Practices to improve support for family members}

In the third main category, perceptions of improving the support for FMs included three categories: allocating resources to the family members' support, coordinated formal and informal support for family members and developing personnel's competence.

Allocating resources to the family members' support meant that the HCPs felt they should be given more resources from the organisation to support families. A better physical environment for families included a need to have improved facilities for FMs to stay and be present in the care unit and a private space to have discussions with them. The HCPs also wished they could have more time for encounters with the families because current timelines and resources in the care units did not allow for adequate support of FMs.

Coordinated formal and informal support for family members described support activities that should be dedicated to the FMs. In general, the HCPs described a need for better consideration of family support, meaning that FMs should be taken into account earlier, more often and systematically. The development of bereavement support was another aspect that the HCPs perceived needed improvement. Again, it was considered to be important to the FMs, but not yet systematically implemented. Informal events for families were mentioned as a development need because FMs wished to have the opportunity to network with other families and also meet the HCPs on informal occasions. 
Developing personnel's competence was described as a need. The HCPs felt that they would benefit from having better communication skills to speak straightforwardly and have better encounters with the FMs. The HCPs also wished that they could have education about family care. Their training was seen as an overall theme that could improve the support for FMs.

\section{Discussion}

This study presented a broad viewpoint of family support from the perspective of three different occupational groups involved in the daily care of palliative care patients. The HCPs perceived that support for FMs included information and emotional support, and they also made suggestions to improve the support for FMs. Information sharing was recognised as an essential element of support, and this communication was carried out actively by the HCPs, whether the FMs were at the care unit or home. Physicians were seen to have the primary responsibility of sharing information about the prognosis and illness trajectory. Registered nurses and practical nurses described information sharing as supporting FMs to internalise and understand the patient's situation and explaining and justifying the treatments and care procedures. The level of knowledge and information-seeking abilities of FMs had developed, and they knew how to question things, which requires HCPs to have the skills and ability to provide appropriate and reasoned answers for them. The importance of fair and honest information sharing, communication, and the effort to make FMs understand the palliative care situation had been observed even in earlier studies [6, 8].

However, the patient's right to reject information sharing caused the HCPs to feel uncomfortable when FMs requested information, but the patient would not give permission. Moreover, the patient's right to autonomy, privacy, and self-determination could inhibit FMs' involvement in the care. There were also problems documenting information that concerned FMs only because they could not be included in patient records [6]. In hospital and inpatient care, the environment has been developed towards patients' needs. However, there were limited opportunities to assess and focus the support of FMs, because the system only allowed the recording of information related to patient data, and FMs did not have a treatment relationship with the unit.

The HCPs described that they made efforts to provide emotional support to FMs to take care of their wellbeing and resilience and organised additional support from outside the care unit. The importance of empathy, having discussions, and listening was emphasised in palliative care, which was seen as a unique situation for FMs, and they had to be treated especially carefully. The meaning of discussions with FMs was underscored, and HCPs felt that they often talked to FMs more than to the patients, which perhaps indicated the FMs' great need for support during palliative inpatient care. The HCPs described several supportive procedures, and they experienced spending many resources supporting FMs emotionally. However, it is remarkable that despite the efforts made by HCPs, FMs often perceive that the emotional support is not sufficient or their emotional care needs are not met $[2,5,6]$. According to these results, there seems to be some discrepancy between the emotional support provided to families and their 
perceived benefit, indicating that although emotional support was given to families, the current support may not always be efficient.

Furthermore, the significance of FMs' participation in patient care was noticed, which was encouraged by the HCPs. Through participation, the FM was thought to feel important, necessary and part of the care. In cancer care settings, FMs' closeness to the patient, the care environment, culture and attitudes in the care unit have vital roles in supporting the FMs [7]. Regarding the perceptions of the HCPs in palliative care, similar aspects of support were seen as necessary. Patient and family togetherness was supported by participating in treatment and by encouraging the FMs' presence. Making the environment receptive was believed to make the family feel welcome, and the HCPs wanted to arrange space and conditions to provide them with an accessible and welcoming atmosphere. In addition, confidential relationships and FMs' trust in good patient care enhanced coping because they could step away from taking care of the patient and relax for a while.

The HCPs made suggestions to improve practices to support FMs, including resources, the need for systematic support and strengthening their competencies in family care. The HCPs experienced that the organisation had not allocated sufficient resources to support families. Patient care was seen as a priority, and the HCPs did not have enough time to meet and talk with the families, even if they wanted to. The HCPs also hoped for better facilities for FMs to have their own space in the care unit, the possibility to stay overnight, and a space to have conversations in private. In general, support focusing exclusively on FMs was needed. A systematic support system for FMs was perceived to be necessary because currently, there was no form of help or guidance for how FMs should be assisted. The health care system was constructed mainly to focus on the patients, and systematic support options and interventions for FMs in inpatient palliative care were absent [5]. Furthermore, an organised bereavement support system was lacking, even though bereavement support would be helpful to assist FMs to cope with the grieving process [3]. In addition, the HCPs described that they would want to have more training in family care in a palliative care setting, and this lack of sufficient training in family care has been stated before [9].

\section{Strengths and limitations}

Purposive sampling may have influenced the selection of participants, but it allowed finding the most applicable informants having experience with the topic. The opportunity to participate was enabled with several interviews arranged in each ward. The participants included physicians and nursing staff, so the perspective of the HCPs who did not participate in the regular care of patients and families remained unheard. The study participants included more nurses and practical nurses than physicians, which may have emphasised their perspective. However, nursing staff represents the largest professional group in inpatient units, and the number of participants was proportional to the number of different professions at the units, as generally, there is only one physician per ward. The interviews were carefully planned and instructed for that all the interviews were conducted as similarly as possible. The data collection, as a whole without separating perspectives of professions, reached a point of saturation, increasing the credibility of the results. However, data saturation regarding different professional groups is not certain. 
The data analysis was performed in a research group, and the COREQ 23-checklist [15] was used to strengthen data analysis and reporting. The participants were not able to see the transcripts or results afterwards to add comments, corrections, or feedback.

\section{Conclusions}

The HCPs perceived that they supported FMs informationally and emotionally, but the support and information were very strongly connected to the patient care and shared through the patient's situation. Currently, the opportunities to implement support focusing directly on FMs was described as restricted. Organisational resources, such as the time to meet the families and appropriate space and environment for FMs, were limited in inpatient units; the HCPs felt they did not have enough time to spend with FMs, while the facilities were not always suitable to support their presence and participation. Additionally, there is a need for organised support systems for FMs that could be implemented in inpatient units by the HCPs as a part of the daily care. Furthermore, additional training for the HCPs in palliative family care is needed.

\section{Declarations}

\section{Funding}

The authors disclosed receipt of the following financial support for the research: The study was partly supported by XXX (blinded for review).

\section{Conflicting interests/Competing interests}

The authors declare that there is no conflict of interest.

\section{Availability of data and material}

The datasets produced and analysed are not publicly available due to the protection of the participants' privacy.

\section{Code availability}

Not applicable.

\section{CRediT authorship contribution statement}

Anu Soikkeli-Jalonen: Conceptualisation, methodology, investigation, data curation, writing (original draft), reviewing, editing, visualisation and funding acquisition.

Kaisa Mishina: Methodology, investigation, writing, reviewing, editing and supervision.

Heli Virtanen: Investigation, writing, reviewing and editing. 
Andreas Charalambous: Writing, reviewing, and editing.

Elina Haavisto: Conceptualisation, methodology, investigation, data curation, writing, reviewing, editing, funding acquisition, supervision and project administration.

\section{Ethics approval}

The study was approved by the Ethics Committee of XXX (CITY blinded for review) University (approval number 15/2019). Research permission was obtained from each hospital accordingly. Furthermore, ethical standards regarding the participants' autonomy, privacy, and anonymity were followed during the study. In addition, written informed consent was obtained from all participants before the study.

\section{Consent to participate}

Written informed consent was obtained from all participants.

\section{Consent for publication}

The participants consented to submit the case report to the journal.

\section{References}

1. LaValley SA (2018) End-of-Life Caregiver Social Support Activation: The Roles of Hospice Clinicians and Professionals. Qual Health Res 28:87-97. doi: 10.1177/1049732317732963.

2. Virdun C, Luckett T, Lorenz K, Davidson PM, Phillips J (2017) Dying in the hospital setting: A metasynthesis identifying the elements of end-of-life care that patients and their families describe as being important. Palliat Med 31:587-601. doi: 10.1177/0269216316673547.

3. Kustanti CY, Fang H, Linda Kang X, Chiou J, Wu S, Yunitri N, Chu H, Chou K (2021) The Effectiveness of Bereavement Support for Adult Family Caregivers in Palliative Care: A Meta-Analysis of Randomized Controlled Trials. J Nurs Scholarsh 53:208-217. doi: 10.1111/jnu.12630.

4. Vermorgen M, De Vleminck A, Leemans K, Van den Block L, Van Audenhove C, Deliens L, Cohen J (2019) Family carer support in home and hospital: a cross-sectional survey of specialised palliative care:bmjspcare-001795. doi: 10.1136/bmjspcare-2019-001795.

5. Soikkeli-Jalonen A, Mishina K, Virtanen H, Charalambous A, Haavisto E (2021) Supportive interventions for family members of very seriously ill patients in inpatient care: A systematic review. J Clin Nurs n/a. doi: https://doi.org/10.1111/jocn.15725.

6. Røen I, Stifoss-Hanssen H, Grande G, Kaasa S, Sand K, Knudsen AK (2019) Supporting carers: health care professionals in need of system improvements and education - a qualitative study. BMC Palliat Care. doi: 10.1186/s12904-019-0444-3.

7. Partanen E, Lemetti T, Haavisto E (2018) Participation of relatives in the care of cancer patients in hospital-A scoping review. Eur J Cancer Care (Engl ) 27:e12821-n/a. doi: 10.1111/ecc.12821. 
8. Anderson RJ, Bloch S, Armstrong M, Stone PC, Low JTS (2019) Communication between healthcare professionals and relatives of patients approaching the end-of-life: A systematic review of qualitative evidence. Palliat Med 33:926-941. doi: 10.1177/0269216319852007.

9. Teixeira MJC, Alvarelhão J, Souza D, Teixeira HJC, Abreu W, Costa N, Machado FAB (2019) Healthcare professionals and volunteers education in palliative care to promote the best practice-an integrative review. Scand J Caring Sci 33:311-328. doi: 10.1111/scs.12651.

10. Ferrell $B$, Wittenberg $E$ (2017) A review of family caregiving intervention trials in oncology. CA Cancer J Clin 67:318-325. doi: 10.3322/caac.21396.

11. Forbat $L$, Johnston N, Mitchell I (2020) Defining 'specialist palliative care': findings from a Delphi study of clinicians. Aust Health Rev 44:313-321. doi: 10.1071/AH18198.

12. Saarto T (2019) Recommendation on the provision and improvement of palliative care services in Finland. Final report of the expert working group. Ministry of Social Affairs and Health. https://julkaisut.valtioneuvosto.fi/bitstream/handle/10024/161946/STM_2019_68_Rap.pdf? sequence=1\&isAllowed=y. Accessed 27.5. 2021.

13. Krueger RA (2015) Focus groups: a practical guide for applied research SAGE, Los Angeles.

14. Elo S, Kääriäinen M, Kanste O, Pölkki T, Utriainen K, Kyngäs H (2014) Qualitative Content Analysis: A Focus on Trustworthiness. SAGE Open 4. doi: 10.1177/2158244014522633.

15. Tong A, Sainsbury P, Craig J (2007) Consolidated criteria for reporting qualitative research (COREQ): a 32-item checklist for interviews and focus groups. Int J Qual Health Care 19:349-357. doi: 10.1093/intqhc/mzm042.

\section{Supplementary Files}

This is a list of supplementary files associated with this preprint. Click to download.

- SCCCOREQ23.pdf 